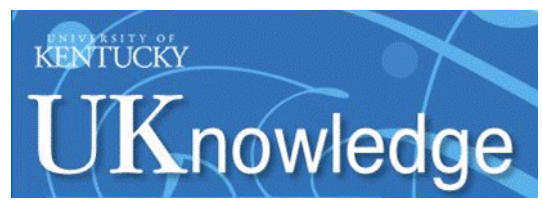

University of Kentucky

UKnowledge

\title{
Street-Based Female Adolescent Puerto Rican Sex Workers: Contextual Issues and Health Needs
}

\author{
Margarita Burgos \\ University of South Carolina - Columbia \\ Donna L. Richter \\ University of South Carolina - Columbia, drichter@mailbox.sc.edu \\ Belinda Reininger \\ University of South Carolina - Columbia, belinda.m.reininger@uth.tmc.edu \\ Ann L. Coker \\ University of South Carolina - Columbia, ann.coker@uky.edu \\ Ruth Saunders \\ University of South Carolina - Columbia, rsaunders@sc.edu
}

See next page for additional authors

Follow this and additional works at: https://uknowledge.uky.edu/crvaw_facpub

Part of the Mental and Social Health Commons, Public Health Commons, Social Work Commons, and the Sociology Commons

Right click to open a feedback form in a new tab to let us know how this document benefits you.

\section{Repository Citation}

Burgos, Margarita; Richter, Donna L.; Reininger, Belinda; Coker, Ann L.; Saunders, Ruth; Alegria, Margarita; and Vera, Mildred, "Street-Based Female Adolescent Puerto Rican Sex Workers: Contextual Issues and Health Needs" (1999). CRVAW Faculty Journal Articles. 134.

https://uknowledge.uky.edu/crvaw_facpub/134

This Article is brought to you for free and open access by the Center for Research on Violence Against Women at UKnowledge. It has been accepted for inclusion in CRVAW Faculty Journal Articles by an authorized administrator of UKnowledge. For more information, please contact UKnowledge@lsv.uky.edu. 


\section{Street-Based Female Adolescent Puerto Rican Sex Workers: Contextual Issues and Health Needs}

\section{Notes/Citation Information}

Published in Family \& Community Health, v. 22, no. 2, p. 59-71.

This manuscript provided with permission from the publisher, and also accessible through the journal's website at http://journals.Iww.com/familyandcommunityhealth/Abstract/1999/07000/

Street_Based_Female_Adolescent_Puerto_Rican_Sex.7.aspx.

Dr. Ann Coker had not been a faculty member of the University of Kentucky at the time of publication.

\section{Authors}

Margarita Burgos, Donna L. Richter, Belinda Reininger, Ann L. Coker, Ruth Saunders, Margarita Alegria, and Mildred Vera 


\title{
6 WHHMPDVHG) HP DOID GROMFHQW PuelWRican $\square \mathrm{SH}$ [WRWHrs: Conte[ tual $\square$ lssues $\square$ and $\square$ Health $\square$ Needs
}

\begin{abstract}
Adolescent sex workers potentially have many health needs but are included rarely in health assessments; therefore, little is known about their needs or how to reach them. This study examines the motivations, social context, and health needs of street-based adolescent sex workers. The results show these youths are more likely to experience negative health outcomes, such as unintended pregnancies and sexually transmitted infections, when they are using drugs or are depressed. These findings suggest the need for comprehensive programming to include individual, interpersonal, and greater environmental interventions. Examples for reaching adolescent sex workers are discussed. Key words: adolescents, females, health needs, Puerto Rico, sex workers, social context
\end{abstract}

\section{$\mathbf{P}$}

UBLIC HEALTH professionals rec-

ognize the need to better serve Hispanic women through culturally competent prevention and treatment programs. However, limited research focuses on the special needs of and services available to specific subgroups of this population. Service needs are assumed to be substantially the same for women as for men and not much attention has been given to appropriate strategies for women. ${ }^{1} \mathrm{Re}$ search indicates that women have special needs that seldom are met. ${ }^{2}$

Beyond the needs for services of Hispanic females is the more specific need to understand socio-cultural characteristics of Hispanic adolescent females. Little is known about motivations, social context, and health needs of female Hispanic adolescents, especially those who trade sex for money, drugs, or other goods.

While public health initiatives are attempting to be more culturally competent and attuned to the needs of priority populations, programming to meet iden- tified needs has remained traditional. All too frequently, the model for providing prevention and treatment-oriented, community-based health services still is based on establishing these services and waiting for clients to utilize them. Insufficient effort is devoted to bringing clients into the system or taking services to them. This service provision dynamic often places people, particularly female youths, in situations in which they are not contacted for services until treatment is required for health problems such as pregnancy, depression, or drug use. This article describes a specific population of youths who are not reached by traditional community-based health services. Their motivations, social context and health needs, and implications for effective service delivery are examined.

This research was supported by grant no. G12-RR03051 to the Center for Evaluation and Sociomedical Research from the National Institutes of Health through the Research Center for Minority Institutions. Fam Community Health 1999;22(2):59-71

(C) 1999 Aspen Publishers, Inc. 


\section{Margarita Burgos, PhD}

Project Director

Department of Health Promotion and Education

\section{Donna L. Richter, EdD}

Associate Professor and Chairperson

Department of Health Promotion and Education

\section{Belinda Reininger, DrPH}

Assistant Professor

Department of Health Promotion and Education

\section{Ann L. Coker, PhD}

Associate Professor

Department of Epidemiology and Biostatistics

\section{Ruth Saunders, PhD}

Assistant Professor

Department of Health Promotion and Education

School of Public Health

University of South Carolina

Columbia, South Carolina

\section{Margarita Alegría, PhD}

Director

Department of Health Administration

Center for Evaluation and

Sociomedical Research

School of Public Health

\section{Mildred Vera, PhD}

Associate Professor

Department of Health Administration

University of Puerto Rico

San Juan, Puerto Rico

\section{LITERATURE REVIEW}

Few studies have been conducted that specifically focus on Hispanic adolescent sex workers and their health needs. However, important previous research on youth risk behaviors, female sex workers, and Hispanic population's health needs has been conducted and will be reviewed for its relevance to this study.

Adolescence is considered a period of transition between childhood and adulthood. ${ }^{3}$ During adolescence, many teenagers initiate sexual activities and begin experimenting with drugs. ${ }^{4}$ This healthdiminishing experimentation often leads to unwanted outcomes, such as unintended pregnancies, drug use, and sexually transmitted infections (STIs). At increased risk of negative health outcomes are: adolescents with multiple sex partners; who have had sexual contact with individuals who inject drugs; who earn a living through trading sex for money, drugs, or other goods; who use drugs (particularly if injected) or alcohol; who are or have been pregnant and continue to be sexually active. ${ }^{5}$ Adolescent sex workers are youths who exchange sex for money, drugs, or other goods. They exhibit most of these risk factors and, therefore, typically possess special health needs.

Research shows that many teenagers initiate sexual activity and drug use $e^{4}$ activities that place them at greater need for prevention and treatment services. Moreover, a correlation between risky sexual behavior and use of illicit drugs among adolescents has been established. ${ }^{6}$ Baker et al. ${ }^{7}$ suggested substance 
use as an important antecedent of sexual risk taking. Research by Szalay, Canino, and Vilov ${ }^{8}$ identified drug use as a problem that particularly affects minorities and youth. Several investigators have demonstrated that the tendency for adolescents to engage in risky behaviors is enhanced when they are under the influence of drugs or alcohol.6,9,10 Kandel ${ }^{11}$ found a strong correlation between $\mathrm{co}^{-}$ caine use and early sexual experimentation, which-while independent of ethnic status-was striking particularly for women. Adolescent female sex workers who use drugs or inject drugs are expected to be more likely to report highrisk sexual practices compared with similar adolescents who are not substance users.

Research conducted by Amaro ${ }^{12}$ showed that depressive mood and depression are related to the use of illegal drugs among Hispanic females. Also, Alegría et al. ${ }^{13}$ found an association between depressive symptoms and negative health outcomes, such as human immunodeficiency virus (HIV) infection. Feelings of powerlessness and depression have been posited as precursors to high-risk practices in women. Thus, drug use and depressive symptomatology seem to influence health behaviors for Hispanic women.

Recently, research has provided some information on the dynamics of the social context surrounding the help-seeking process among Hispanics. ${ }^{14}$ The importance of family relationships in the development of risk practices consistently has been documented. ${ }^{15,16}$ The Hispanic family is a central institution in which close family ties and obligations are strongly fostered. ${ }^{17,18}$ Support from the family of origin and positive family interaction are seen as protective factors that can mitigate the risks for risky practices. ${ }^{19}$ The social context factor gains particular relevance for this study population because Puerto Rican women sustain a high level of interaction with their family of origin. For Hispanic women, the primary role of the family and friends is to buffer adversity (both internal and external) and to maximize or minimize the impact of exposure to positive/negative rewards promoted by interpersonal interactions. However, unreasonably high expectations of Hispanic females and their multiple roles (such as wife, mother, daughter) sometimes can lead to stress and depression. ${ }^{20}$

While social influences can be a preventive influence for some female adolescents, others may find associates in sex work who are negative influences on their behaviors in the areas of drugs and condom use. Research with drug-using women shows that significant others, especially family members and sexual partners, have a strong influence on the lives of females. ${ }^{21}$ Sexual partners frequently introduce women to injecting drugs. Bresnahan et al. ${ }^{22}$ pointed to a nearly fivefold increase in drugs and heavy alco-

\section{Female adolescent Hispanic sex workers, based on the literature, appear to be at increased risk for negative health outcomes such as drug use, depression, STIs, and unwanted pregnancies.}


hol use by women whose partners also were drug or alcohol users. Women who report having first used drugs in the company of intimate others-lovers and kin-rather than with friends or alone display higher consumption and more prolonged use of drugs. ${ }^{23}$

Female adolescent Hispanic sex workers, based on the literature, appear to be at increased risk for negative health outcomes such as drug use, depression, STIs, and unwanted pregnancies. Additionally, youths' social context seems to play an important role in their motivations to engage in sex work.

\section{METHODS}

This study is based on data collected through personal interviews of streetbased female adolescent sex workers in Puerto Rico. The sample consisted of 78 female adolescents who traded sex for money, drugs, or other goods. Individuals age 13-18 were eligible to participate in the study. Six recruitment sites in diverse areas of Puerto Rico were targeted. These sites usually were within or adjacent to public housing or areas where drugs were sold. Public health outreach workers from the Department of Health in Puerto Rico established initial contacts and obtained the participants' informed consent to participate in the study. Participants received a financial incentive for their time and effort. While not selected at random, this sample provides preliminary information about adolescent sex workers in Puerto Rico.

Personal interviews with the respondents lasted 45-60 minutes. Information about demographics, motivational and social context, health, and behavioral factors were collected. General demographic data were collected. Questions regarding marital status, number of children, and educational status, among others, were asked.

Participants were asked to provide the motivations surrounding their initiation of sex work. These data were sorted and categorized by themes. Motivational factors were attributed either to social/psychological issues, finances, or other. Two questions were asked regarding the social context of participants when they started in sex work. Specifically, role modeling by friends or relatives was examined.

Various indicators of health status were considered. Services used, such as visits to physicians and hospitalizations, level of depressive symptoms, positive STI test results, and sexual behaviors, were some of these measures.

The Center for Epidemiological Studies Depression Scale (CES-D) ${ }^{24}$ was used to establish the current level of depression of each participant. This scale, used previously with Puerto Ricans, ${ }^{25}$ corresponds to depressive symptoms experienced by the study participant during a period of a week previous to its administration. A cutoff point of 16 has been accepted as appropriate for identifying individuals with an elevated number of symptoms, such as sex workers. ${ }^{13}$ This cutoff point was used for this study.

Bodily fluid samples also were collected from participants. Medical personnel were responsible for the collection of blood and cultures for STI tests. Blood samples were tested for antibodies against HIV and syphilis. Cultures were tested for gonorrhea and chlamydia. 
Drug use was analyzed according to two categories. Those participants who reported using no drugs or consuming only alcohol belonged to one category. The category labeled other drugs corresponded to use of illegal drugs such as marijuana, cocaine, crack, heroin, a combination of these, or other illegal drugs. Respondents within this category might have or might not have used alcohol in combination with other drugs.

Sexual practices were included among the health-enhancing/diminishing behaviors. Non-paying sexual partners and the number of clients were considered. Also, preventive measures such as condom use with both non-paying sexual partners and clients were analyzed.

Following the interview and sample collection, each participant attended counseling sessions in which information about protection against STIs was provided. Condoms were distributed and treatment for STIs was administered when needed.

\section{ANALYSIS}

The Statistical Analysis System ${ }^{13}$ was used to perform the analyses for this study. Frequencies for the population with respect to the sociodemographics, motivations and social context, and health status and practices have been used to describe the sample.

\section{RESULTS}

\section{Demographic characteristics}

Street-based female adolescent sex workers were recruited in low socioeco- nomic settings and nearby residential areas. Table 1 shows the results for the demographic variables. The mean age of participants was 16 years. The majority of participants $(87.2 \%)$ were born in Puerto Rico. More than half were single (52.6\%), with almost 40 percent living with a partner (19.2\%) or separated (19.2\%). About half of the interviewees had one or more children (48.7\%). Almost 60 percent of the participants (59.0\%) reported living with their parents; 23 percent were living with someone else without paying rent; 16.7 percent rented or owned their own home; and one lived on the streets. The mean number of years in school was 8.3, with a standard deviation of 1.8 years. About two thirds of the sample were high school drop outs (62.8\%).

Participants were asked the reason or reasons to drop out of school. Some of the main reasons to drop out of school, according to the participants, were: they did not like school (47.2\%), school was boring (43.4\%), they had problems with teachers (34.0\%), they flunked (26.4\%), they got pregnant (20.8\%), and their parents did not care (17\%). Other reasons, such as being suspended, having to work to earn a living, moving to another town, or problems with access to school (such as transportation or distance), accounted for 10 percent or less each.

Participants were asked who raised them during most of their childhood. More than half of the participants (55.1\%) reported being raised by a single biological mother. Almost one fifth $(19.2 \%)$ reported being raised by both biological parents; while just more than one tenth $(11.5 \%)$ reported being raised 
Table 1. Frequency and percent distribution of demographic factors of street-based female, adolescent, Puerto Rican sex workers $(\mathrm{N}=78)$

\begin{tabular}{|lrr|}
\hline \multicolumn{1}{|c|}{ Variable } & N & \% \\
\hline Age & & \\
13 years & 4 & 5.0 \\
14 years & 8 & 10.3 \\
15 years & 8 & 10.3 \\
16 years & 17 & 21.8 \\
17 years & 33 & 42.3 \\
18 years & 8 & 10.3 \\
Place of birth & & \\
Puerto Rico & 68 & 87.2 \\
United States & 10 & 12.8 \\
Marital status & & \\
Single & 41 & 52.6 \\
Living with someone & 15 & 19.2 \\
Married & 1 & 1.3 \\
Separated & 15 & 19.2 \\
Divorced & 4 & 5.1 \\
Widowed & 2 & 2.6 \\
Number of children & & \\
None & 40 & 51.3 \\
One & 32 & 41.0 \\
Two & 4 & 5.1 \\
Three & 2 & 2.6 \\
Living arrangements & & \\
Living with parents & 46 & 59.0 \\
Living with someone else & & \\
$\quad$ without paying rent & 18 & 23.0 \\
House owned or rented & 13 & 16.7 \\
On the streets & 1 & 1.3 \\
Education & & \\
Studying & 29 & 37.2 \\
Drop-out & 49 & 62.8 \\
Raised by & & \\
Single biological mother & 43 & 55.1 \\
Single biological father & 3 & 3.9 \\
Both biological parents & 15 & 19.2 \\
Grandparents & 11.5 \\
Other & & \\
\hline
\end{tabular}

by grandparents. Participants raised by other relatives accounted for 10.3 percent. Only 3.9 percent of the respondents reported being raised by the biological father.

\section{Motivations and social context}

Participants were asked to share their motivations for becoming involved in sex work. Issues related to money were the most common response given by participants (Table 2). Three fourths of the sample reported needing the money as their primary motivation. Of those who

Table 2. Frequency and percent distribution of motivations to initiate sex work and social context of street-based female, adolescent, Puerto Rican sex workers ( $\mathrm{N}=78$ )

\begin{tabular}{|lrr|}
\hline \multicolumn{1}{|c|}{ Variable } & N & \% \\
\hline $\begin{array}{l}\text { Motivational factors } \\
\text { Social/psychological factors }\end{array}$ & 20 & 25.6 \\
Lack of perceived & & \\
alternatives & 1 & 1.3 \\
Problems at home/with & & \\
parents & 8 & 10.3 \\
$\quad$ Curiosity/rebelliousness & 8 & 10.3 \\
Financial factors & 58 & 75.4 \\
$\quad$ To buy/get drugs & 5 & 6.4 \\
$\quad$ General financial needs & 23 & 29.5 \\
Money for material things & 17 & 21.8 \\
Money for family & 9 & 11.5 \\
Money for basic needs & 4 & 5.1 \\
Other & 3 & 3.8 \\
Social context & & \\
Friend in prostitution & & \\
$\quad$ No & 23 & 29.5 \\
$\quad$ Yes & 55 & 70.5 \\
Relative in prostitution & & \\
No & 50 & 64.1 \\
$\quad$ Yes & 28 & 35.9 \\
\hline
\end{tabular}


reported money as their main motivation, 5.1 percent specified that they needed it for their basic needs (such as shelter and food); 11.5 percent said they did it to help their families. Almost 30 percent stated they just needed the money, while 22 percent specified they wanted the money for material needs (such as clothing, shoes, jewelry, outings). Only 6.4 percent attributed their initiation into sex work to drug use.

One fourth of the sample said they started doing sex work for reasons not related to financial needs, such as having problems at home. Ten percent of the respondents stated that sex work was the only source of income after they had to abandon their homes due to constant arguments with their parents, guardians, or husbands.

These adolescents were asked about friends and relatives who were in sex work. More than two thirds of the participants said that they had a friend in prostitution before they started. One third of the respondents reported having a relative who also was a sex worker.

Researchers made observations during the data collection activities. These observations were based on informal conversations with participants while they waited to be interviewed or before they were seen by medical personnel to collect the bodily fluid samples. Based on these observations, the researchers believe most adolescents perceived sex work as a transient source of income. Participants stated that this was something they were doing temporarily to meet their needs. When asked about plans for the future, some of them mentioned going back to school or getting a job when they reached the age when they could start working. However, steps toward meeting these goals were not being taken. For some, because of children, going back to school or having other sources of income were not options. Even so, the majority of the adolescent sex workers perceived their sex work as temporary.

\section{Health status and health enhancing/diminishing practices}

\section{Medical services}

Almost 60 percent of the participants had seen a physician during the year previous to the interview (Table 3). Twentyeight percent had been hospitalized during the previous year and two thirds of these hospitalizations were due to live childbirth.

\section{Level of depressive symptoms}

The level of depressive symptoms was calculated for each respondent. Almost two thirds of the adolescents interviewed displayed high levels of depressive symptoms.

\section{Positive STI test results}

Results for the STI tests showed that less than one tenth of the participants had a positive test result for syphilis. Cases were confirmed with the microhemoagglutination test (MHA-TP). Thus, only active cases were considered for the analysis. Results for gonorrhea included tests for oral, anal, and cervical samples. No cases of gonorrhea were found. Positive results for chlamydia occurred in 12.8 percent of the study participants. 
Table 3. Frequency and percent distribution of health status and practices of streetbased female, adolescent, Puerto Rican sex workers $(\mathrm{N}=78)$

\begin{tabular}{|c|c|c|}
\hline Variable & $\mathbf{N}$ & $\%$ \\
\hline \multicolumn{3}{|l|}{ Health status } \\
\hline \multicolumn{3}{|c|}{$\begin{array}{l}\text { Seen a doctor during the } \\
\text { last year }\end{array}$} \\
\hline No & 32 & 41.0 \\
\hline Yes & 46 & 59.0 \\
\hline \multicolumn{3}{|c|}{$\begin{array}{l}\text { Hospitalizations during the } \\
\text { last year }\end{array}$} \\
\hline No & 56 & 71.8 \\
\hline Live child birth & 15 & 19.2 \\
\hline Other reason & 9 & 9.0 \\
\hline \multicolumn{3}{|l|}{$\begin{array}{l}\text { Level of depressive } \\
\text { symptoms }\end{array}$} \\
\hline Low & 28 & 35.9 \\
\hline High & 50 & 64.1 \\
\hline \multicolumn{3}{|l|}{ Positive STI test } \\
\hline Syphilis & 6 & 7.7 \\
\hline Gonorrhea & 0 & - \\
\hline Chlamydia & 10 & 2.8 \\
\hline HIV & 2 & 2.6 \\
\hline \multicolumn{3}{|c|}{$\begin{array}{l}\text { Health-enhancing/diminishing } \\
\text { practices }\end{array}$} \\
\hline \multicolumn{3}{|c|}{ Drug use } \\
\hline No drug use & 28 & 35.9 \\
\hline Alcohol only & 15 & 19.2 \\
\hline Other drugs & 35 & 44.9 \\
\hline \multicolumn{3}{|c|}{$\begin{array}{l}\text { Non-paying sexual partner } \\
\text { (last six months) }\end{array}$} \\
\hline No & 24 & 30.8 \\
\hline Yes & 54 & 69.2 \\
\hline \multicolumn{3}{|c|}{$\begin{array}{l}\text { Condom use with non- } \\
\text { paying sexual partner }\end{array}$} \\
\hline Always & 13 & 16.7 \\
\hline Not always & 41 & 52.5 \\
\hline No partner & 24 & 30.8 \\
\hline \multicolumn{3}{|c|}{ Number of clients (per day) } \\
\hline One & 32 & 41.0 \\
\hline Two & 17 & 21.8 \\
\hline Three or more & 29 & 37.2 \\
\hline \multicolumn{3}{|c|}{ Condom use with clients } \\
\hline Always & 38 & 48.7 \\
\hline Not always & 40 & 51.3 \\
\hline
\end{tabular}

Only two participants had a positive test result for HIV antibodies (2.6\%). Overall, 15 participants (19.2\%) tested positive for current syphilis, chlamydia, or HIV infection.

\section{Drug use}

Drug use was classified into three categories: no drug use, alcohol use only, or use of other drugs including marijuana, cocaine, crack, and other illegal drugs. Participants reporting illegal drug use might or might not have used alcohol in combination with other drugs. More than one third (35.9\%) of the participants had not used any drugs during the six months previous to the interview. Almost one fifth (19.2\%) of the participants reported having used only alcohol during the previous six months, while 44.9 percent of the participants reported other drug use during the same period of time.

\section{Non-paying sexual partners}

Participants were asked whether they had had sexual partners who were not paying clients during the six months previous to the interview. More than two thirds $(69.2 \%)$ of the adolescents interviewed reported having a non-paying sexual partner during the last six months. More than half (52.5\%) of those who had non-paying sexual partners reported inconsistent or no condom use with them.

\section{Clients}

The report of the number of clients with whom participants had sex per day ranged from 1 to 10 . The average number of clients per day was 2.5 , with a standard deviation of 1.9 clients. More than two thirds (69\%) of the adolescents 
interviewed reported having two clients or more per day. Almost half of the adolescents interviewed reported inconsistent or no condom use with their clients.

\section{DISCUSSION}

This study examined the social context, motivations, and health needs of street-based female adolescent sex workers in Puerto Rico. Results from this study show that the most important factor driving adolescents into sex work is their financial situation. Some participants perceived sex work as a source of income to help sustain themselves or their families. However, most adolescents considered sex work as the means to fulfill their need for material things. Social context and exposure to media that are filled with images of material wealth and beauty encourage adolescents to desire more material possessions. This exposure can frame the priorities of adolescents. In some cases, obtaining material goods becomes their top priority for which they sacrifice health, safety, and emotional balance. Furthermore, having friends or relatives who are also sex workers contributed to adolescents' perception of sex work as a viable alternative for them. Research shows that Hispanics engage in certain behaviors because they are consistent with family values. Thus, adolescents with relatives who do sex work are more likely to consider this alternative to fulfill their needs.

This study also provided insights into the health status of Hispanic adolescent sex workers. This study found 19 percent adolescents with an STI and 49 percent who had children. Results show a large number of participants were using drugs. Also, high levels of depressive symptoms were found among the sample. Although drugs such as alcohol, marijuana, or cocaine do not expose one to organisms that cause negative health outcomes such as unwanted pregnancies or STI, their use often decreases one's use of preventive measures.

\section{IMPLICATIONS FOR COMMUNITY INTERVENTIONS}

Designing effective prevention strategies for adolescent sex workers is an enormous challenge. The findings of this study point to the tremendous need to do ecologically based prevention programming. ${ }^{26}$ As with all adolescents, these Hispanic adolescent sex workers have individual, interpersonal, and larger environmental factors impacting their behaviors. Therefore, the authors recommend multicomponent programming across the individual, interpersonal, and environmental levels to prevent health-diminishing behaviors.

At the individual level, risk-reduction strategies among sex workers should take into consideration the level of distress they experience from various stressors, including caring for children. Results from this study show that most of these adolescents had at least one child. Additionally, strategies to help adolescents identify the signs of depressive symptoms and develop skills to counteract the effects of depression should be addressed during interventions. The development of strong communication skills that enable adolescents to act on 


\section{Adolescent sex workers with enhanced self esteem and self efficacy will be able to set their own boundaries for sexual activity and other risk- taking behaviors.}

decisions they make about their sexual behavior is recommended. ${ }^{27}$ Adolescent sex workers with enhanced self esteem and self efficacy will be able to set their own boundaries for sexual activity and other risk-taking behaviors.

At the interpersonal level, multiple interventions could be designed to infuse new information and develop healthy attitudes about condom use, drug use, and alternative options for employment. This study found that many of the participants had either relatives or friends in sex work. Interventions using a train the trainer methodology may be appropriate to work within these adolescents' social network and change behaviors that are jeopardizing their health and well-being. Also, strategies should be developed to counteract the perception that sex work is a safe and quick alternative to fulfill their needs. To fully complement interpersonal changes in their relationships, these strategies must consider viable sources for employment and offer vocational training.

Just as individual and interpersonal changes are important, environmentallevel interventions should be implemented. Results from this study indicate that traditional services are not reaching this sector of the population. Many of these adolescents are drop outs and therefore cannot be reached within the school setting. Yet, 20 percent had an STI, 45 percent were using illegal drugs, and 64 percent had a high level of depressive symptoms-all indicators of poorer health. The need for intensive outreach to target people who do not access services is evident. Intensive, nontraditional services that are taken into the communities are one alternative. Some examples of environmental interventions would be altering the way drug treatment and health services are provided.

In Puerto Rico, drug treatment services currently are hard to access, have unreasonable expectations for admission, have inappropriate modalities for the treatment of adolescents, and most do not allow women to have their children with them. Therefore, in order to jointly address effectively substance abuse, creative and appealing strategies for adolescent sex workers need to be developed, implemented, and evaluated.

Additionally, youth service programming must be comprehensive and proactive in its nature. Behaviors and conditions such as drug use, risky sexual practices, and depression cannot be isolated. These health problems are related in the population of adolescent sex workers and need to be addressed holistically.

Finally, seeking health care is a central issue in controlling negative health outcomes such as pregnancy and STIs in female adolescent, Hispanic sex workers. Females delay seeking health care longer than men do. ${ }^{28}$ Multiple factors contribute to their delay in seeking health care. Barriers to accessing the system as well as stigma are some of the factors mentioned by these adolescents. Locating 
health services in high-risk neighborhoods has been suggested as a strategy to overcome these barriers. ${ }^{4}$ Additionally, the provision of child care removes a barrier, especially for women. Eliminating the time between setting an appointment and the actual delivery of services is the key in the prevention of unwanted outcomes. Also, outreach strategies must include youth-friendly health workers. People with whom adolescents can relate and feel comfortable discussing their risks and concerns during counseling sessions improves the chances of these efforts to be more effective. Health workers cannot wait for these adolescents to come to the clinics. Services and counseling need to be delivered on site, with reasonable or no waiting time, and walk-ins must be welcomed.

The effectiveness of these ecologically based prevention strategies should be tested. As suggested by Smith, Weinman, and Mumford, ${ }^{29}$ when and if behavior is altered, understanding the mechanisms for change becomes the key for future and improved interventions.

Ideally, in addition to individual, interpersonal, and environmental changes designed to impact health-diminishing behaviors, additional strategies need to be implemented to address the socio-cultural norms for the desire of material goods. As previously mentioned, this desire influences young women to use sex work as a means to obtain material goods such as jewelry, clothing, and shoes. Society must take a look at its values more closely when young people place themselves at increased risk of a lower quality of life while pursuing the high life. This tendency is apparent in more and more societies, not just in Puerto Rico.

This study is an attempt to explain motivations, social context, and health needs among street-based female adolescent, Puerto Rican sex workers. The cross-sectional design of the study hampers the possibility of determining causality. The recruitment of participants basically was dependent on the availability of subjects. Nevertheless, given the illegal nature of prostitution, the age of the subjects and their fear of participating in research projects, this kind of sampling technique was the most appropriate for recruitment. Though not a probabilistic sample, this study provides representation of adolescent sex workers throughout Puerto Rico.

\section{SUMMARY}

Adolescents who perform sex work as a means to earn a living or to temporarily meet their needs should be considered a priority for preventive interventions. Little understanding exists about the range of contexts in which sex is exchanged for money, goods, services, or accommodation-circumstances not necessarily perceived as direct sex work. ${ }^{30}$ Their perception of sex work as a temporary source of income implies that sex work might be a stage of their life that they might outgrow with time. Community health workers should strive for comprehensive programming because adolescent behavioral choices are not related just to knowledge and interpersonal relationships, but to societal norms. 


\section{REFERENCES}

1. Beschner G, Thompson P. Women and Drug Abuse Treatment: Needs and Services. Rockville, MD: National Institute of Drug Abuse; 1981. Publication ADM 81-1057.

2. Reed B. Intervention strategies for drug dependent women: An introduction. In: Treatment Services for Drug Dependent Women. Vol. I. Rockville, MD: National Institute of Drug Abuse; 1981.

3. Langer LM, Warheit GJ. The pre-adult health decision-making model: Linking decision-making directedness/orientation to adolescent health-related attitudes and behavior. Adolesc. 1992;27(108): 919-948.

4. Yarber WI, Parrillo AV. Adolescents and sexually transmitted diseases. $J$ of Sch Health. 1992;62(7): 331-338.

5. Williams E, Wilkins R. U.S. Preventive Services Task Force. Counseling to prevent human immunodeficiency virus infection and other sexually transmitted diseases. In: Guide to Clinical Preventive Services. Baltimore; U.S. Preventive Services Task Force; 1989.

6. Richter DL, Valois RF, McKeown RE, Vincen ML. Correlates of condom use and number of sexual partners among high school adolescents. $J$ of Sch Health. 1993;63(2):91-96.

7. Baker SA, Morrison DM, Gillmore MR, Schock MD. Sexual behaviors, substance abuse and condom use in a sexually transmitted disease clinic. The $J$ of Sex Res. 1995;32(1):37-44.

8. Szalay L, Canino G, Vilov S. Vulnerabilities and cultural change: drug use among Puerto Rican Adolescents in the United States. The Int $J$ of the Addict. 1993;28(4):327-354.

9. Mott F, Hawrin R. Linkages between sexual activity and alcohol and drug use among American adolescents. Fam Plann Perspect. 1988;20:128.

10. Bentler P, Newcomb M. Cocaine use among adolescents: Longitudinal associations with social context, psychopathology, and use of other substances. $J$ of Addictive Behaviors. 1986;11:263-273.

11. Kandel D. On process of peer influences in adolescent drug use: A developmental perspective. Adv in Alcohol and Substance Abuse. 1985;4:3-4.

12. Amaro H, Fried L, Cabral H, Zuckerman B. Violence during pregnancy and substance abuse. Am J of Public Health. 1990;80(5):575-579.

13. Alegría M, et al. HIV infection, risk behaviors, and depressive symptoms among Puerto Rican sex workers. Am J of Public Health. 1994;84(12): 2000-2002.

14. Cervantes RC, Garcia I. Alcohol abuse prevention research in the hispanic community. In: The Challenge of Participatory Research: Preventing Alcohol-Related Problems in Ethnic Communities. CSAP Cultural Competence Series. Washington, DC: Department of Health and Human Services; 1992.

15. Brook JS. Personality, family, and ecological influences on adolescent drug use: A developmental analysis. J of Chemical Dependency Treat. 1988; 2:123-162.

16. Brook JS, Brook DW, Gordon AS, Whiteman M, Cohen P. The Psychosocial Etiology of Adolescent Drug Use: A Family Interactional Approach. Genet Psychol Monog. 90;116(2).

17. Canino IA, Earley BF, Rogler RH. The Puerto Rican Child in New York City: Stress and Mental Health. Monograph 4. New York: Fordham University, Hispanic Research Center; 1980.

18. Cushner K. Culturally specific approaches to knowing, thinking, perceiving, and understanding. In: Advance Methodological Issues in Culturally Competent Evaluation for Substance Abuse Prevention. CSAP Cultural Competence Series, Vol. 6. ; 1996.

19. Brook JS. Interactional Theory: Its Utility in Explaining Drug Use Behavior among AfricanAmerican and Puerto Rican Youth. Monograph Series. Washington, DC: National Institutes on Drug Abuse, Department of Health and Human Services; 1983.

20. Pearlin LI. The sociological study of stress. $J$ of Health and Social Behav. 1989;30(3):241-256.

21. Stenbacka M. Initiation into intravenous drug abuse. Acta Psychiatr Scand. 1990;81:459-462.

22. Breshnan K, Zuckerman B, Cabral H. Psychosocial correlates of drug and heavy alcohol use among pregnant women at risk for drug use. Pregnancy and Drug Use. 1992;80:6.

23. Gerstein D, Judd L, Rouner S. Career dynamics of female heroin addicts. Am J of Alcohol and Drug Abuse. 1979;6:1-23.

24. Radloff L. The CES-D Scale: A self-report depression scale for research in the general population. Appl Psychol Meas. 1978;1(3):385-401.

25. Vera M, Alegría M, Freeman D. Depressive symptoms among Puerto Ricans: Island poor compared with residents of the New York City area. Am J of Epidemiol. 1991;134:502-510.

26. McLeroy KR, Bibeau D, Steckler A, Glanz K. An ecological perspective on health promotion programs. Health Educ Q. 1988;15(4):351-377.

27. Centers for Disease Control and Prevention. Sexual 
behavior among high school students-United States, 1990. Morbidity and Mortality Weekly Rep. 1992;40:885-888.

28. Fortenberry J. Health care seeking behaviors related to sexually transmitted diseases among adolescents. Am J of Public Health. 1997;87(3):417420.

29. Smith PB, Weinman M, Mumford DM. Knowledge, beliefs, and behavioral risk factors for human immunodeficiency virus infection in inner city adolescent females. Sex Transm Dis. 1992;19(1):19-24.

30. Stein Z, Kuhn L. HIV in women: What are the gaps in knowledge? In: Mann J. Tarantola, D., eds. AIDS in the World II. New York: Oxford University Press; 1996. 